\title{
Prevalence and determinants of unconscious stereotyping among primary care physicians
}

\author{
An analytical cross-section study
}

Naif M. Alqahtani, MBBS, MPH, Shehata F. Shehata, MBBS, PhD, Ossama A. Mostafa, MPH, PhD.

\begin{abstract}
الأهداف : استكشاف الصور النمطية غير المقصودة لدى أطباء الرعاية

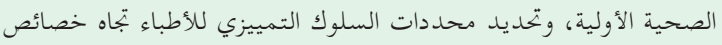

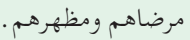

المنهجية : اتبع هذا البحث نسق الدراسة المستعرضة التحليلية، ولقد تم إجراؤه

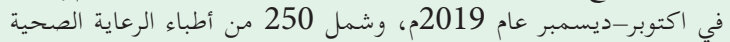

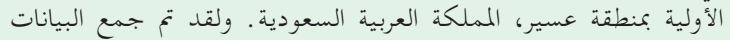

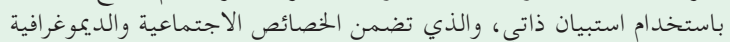

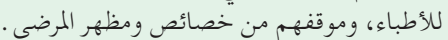

النتائج: كان معدل انتشار الصور النمطية بين أطباء الرعاية الصحية الأولية

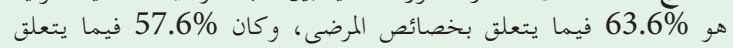

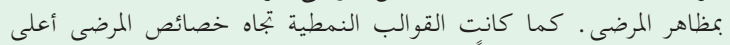

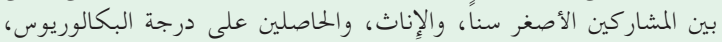
والممارسين العموميين.

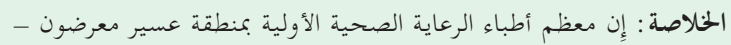

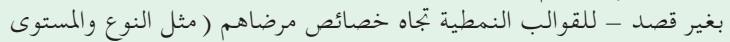

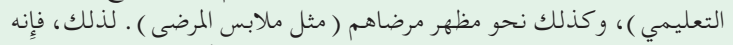

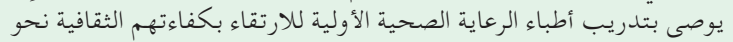

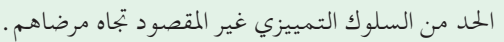

Objectives: To explore implicit stereotyping among primary healthcare (PHC) physicians and to identify determinants of physicians' stereotyping of patients based on the patients' characteristics and appearance.

Methods: This study followed an analytical cross-sectional design conducted between October 2019 and December 2019, and included 250 primary healthcare (PHC) physicians in Aseer Region, Kingdom of Saudi Arabia. Data was collected using a self-administered questionnaire, which included items concerning physicians' sociodemographic characteristics, and their attitudes toward patient characteristics and patient appearance.

Results: Prevalence of stereotyping among PHC physicians was $63.6 \%$ with respect to patient characteristics and $57.6 \%$ with respect to patient appearance. Stereotyping based on patient characteristics was higher among younger participants, females, those with bachelor's degrees, those in general practitioner positions, and those with less experience in PHC.

Conclusion: Most PHC physicians in Aseer Region, Kingdom of Saudi Arabia, are liable to implicit stereotyping based on patient characteristics (namely, gender and educational level) and patient appearance (namely, clothing). Therefore, it is recommended to train PHC physicians in cultural competency to reduce unintentional acts of discrimination toward their patients.

Keywords: prevalence, stereotyped behavior, primary health care, cross sectional analysis, Saudi Arabia, logistic regression

Saudi Med J 2020; Vol. 41 (8): 858-865

doi: 10.15537/smj.2020.8.25186

From the Ministry of Health (Alqahtani), Aseer, and from the College of Medicine (Shehata, Mostafa), King Khalid University, Abha, Kingdom of Saudi Arabia.

Received 12th March 2020. Accepted 24th June 2020.

Address correspondence and reprint request to: Dr. Naif M. Alqahtani, Ministry of Health, Aseer, Kingdom of Saudi Arabia.E-mail: naif-454@hotmail.com

ORCID ID: https://orcid.org/0000-0002-5809-6530

$\mathrm{T}$ here is a growing evidence suggesting that physicians' attitudes and decision-making contribute significantly to stereotypes that may cause disparities in provided healthcare. ${ }^{1,2}$ Nevertheless, little is known about why patient stereotyping by physicians influences the process of their clinical decision-making, and thus, there is an insufficient evidence for directing intervention priorities and strategies. ${ }^{3}$ The reasons for such disparities are associated with several factors: 
genetic or biological antecedents, socioeconomic predictors, and psychological processes that can build up inter-group. ${ }^{4}$

Stereotypes are noticeable among different psychological biases, that may lead to various disparities in health outcomes, which are culturally spread. Many experiments have shown that stereotypes can implicitly affect the judgment and behavior of lay people, while several studies have shown that prejudice and stereotyping impact how physicians diagnose and treat their patients. ${ }^{3,5}$ Stereotyping happens in 2 levels. The first includes cognitive processes that control stereotype activation, while the second includes cognitive processes that decide whether stereotypes are used in assessment, judgment, and actions toward others. ${ }^{6}$ Dehon et $\mathrm{al}^{7}$ noted that, even when physicians are well informed toward cultural differences and psychological biases, there are occasions when they depend on stereotypes when they provide healthcare. This can occur, even with low-prejudiced, well-intentioned physicians, who may stereotype certain persons when they feel exhausted, cognitively overpowered, or are expected to make quick decisions using inadequate information. There are several strategies for diminishing the activation and use of negative stereotypes, attitudes and behaviors in judgment and interaction. ${ }^{8}$ For example, training physicians in cultural competence can play a significant role in decreasing behaviors that may discourage some patients from using available health services and in diminishing implicit acts of discrimination that prevent minority members in the community from getting the care they demand and deserve. ${ }^{4}$ Nevertheless, it is to be noted that despite the potential influence of discriminatory behavior of physicians on the quality of provided healthcare, there were few studies on the effects of doctors' perceptions and beliefs regarding characteristics and appearance of their patients. Although limited literature indicated that physicians' unconscious attitudes are triggered when dealing with certain patients, these studies did not show that doctors may also have triggered stereotypes.

This study aimed to explore implicit stereotyping among primary healthcare (PHC) physicians and to identify determinants of physicians' discriminatory behavior toward their patients' characteristics and appearance.

Disclosure. Authors have no conflict of interests, and the work was not supported or funded by any drug company.
The hypothesis of this study was that most physicians in Aseer Region, Kingdom of Saudi Arabia (KSA), unconsciously (namely, implicitly) stereotype based on their patients' characteristics or appearance while providing PHC service.

Methods. After meticulous search in medical databases (PubMed and Ovid), no other studies exploring stereotyping and its impact among PHC physicians in KSA could be found.

In this study, implicit stereotyping is defined as categorizations used by physicians to make judgments about patients. ${ }^{9}$ Social discrimination is differentiating treatment of patients based on their appearance or actual characteristics (example, nationality, age, gender, monthly income, or medical condition). ${ }^{10}$ Primary healthcare physicians are those who provide clinical service (preventive and curative) to primary care patients, including dentists (like oral physicians). ${ }^{11}$

This research employed an analytical cross-sectional study design. It was conducted at PHC centers in Aseer Region, KSA, at the southwestern part of KSA. The study was carried out between October 2019 and December 2019. According to data of Aseer Directorate of Health, the study population included all 509 PHC physicians (including dentists) at 240 PHC centers across 19 geographical sectors in Aseer Region, KSA. Using the Raosoft sample size calculator website, the minimum sample size was calculated for the present study to be 220 , with $5 \%$ error margin, $95 \%$ level of confidence, total population of 509, and an expected response distribution of $50 \% .^{12}$

Following a cluster sampling technique, 10 out of the total of 19 geographical sectors in Aseer Region, KSA, were randomly selected. All PHC centers within each selected sector were included, and hence, a total of 300 PHC physicians, including dentists, were asked to participate in this study. However, only 250 physicians agreed and filled their questionnaire sheets completely, giving a response rate of $83.3 \%$. The reasons for non-willingness to participate were mainly absence of physicians at the time of visit.

General practitioners, family physicians, dentists, and physicians with other clinical specialties at primary care facilities were included. On the other hand, physicians with administrative positions were excluded. Data was collected using a self-administered questionnaire, which was developed by the researchers and based on review of relevant literature. ${ }^{13,14}$ It included the following parts: i) physician's sociodemographic characteristics; ii) physician's attitude toward different personal and sociodemographic characteristics of their 
patients (9 items); and, iii) physician's attitude toward their patients' appearance (6 items).

The validity of the study questionnaire (namely, face and content validity) was assessed by 2 academic professors of public health and psychiatry at King Khalid College of Medicine, KSA. Participants' attitudes were assessed using statements accompanied by a 5-point Likert scale with the following levels: strongly agree, agree, neutral, disagree, or strongly disagree. An attitude score was assigned for each statement according to the response on the scale: $(-2)$ for strongly disagree, $(-1)$ for disagree, (0) for neutral, $(+1)$ for agree, and $(+2)$ for strongly agree. The total score for each participant was summed. Physicians with scores above 0 were considered stereotyping, while those with total scores of 0 or less were considered non-stereotyping.

A pilot study was carried out on 15 PHC physicians, whose responses were excluded from the main study. One week later, the researchers re-interviewed the same participants, using the study questionnaire. The objective of the pilot study was to test the data collection tool, to estimate the time needed to complete the questionnaire, and to assess its test-retest reliability ( $\mathrm{r}=0.92$ for physicians' attitudes toward patient characteristics and $\mathrm{r}=0.85$ for physicians' attitudes toward patient appearance). Moreover, for the assessment of internal consistency of the study tool, Cronbach's alpha reliability coefficient was calculated, with $\alpha=0.77$ for physicians' attitudes toward patient characteristics and $\alpha=0.81$ for physicians' attitudes toward patient appearance.

All PHC centers within a selected geographic sector were visited by the researchers. All physicians fulfilling the inclusion criteria at the visited PHC center were invited to participate. Physicians were interviewed during their break time. Objectives of the study were briefly and clearly explained to each potential participant. They were assured that no harm was expected to occur if they participated in this study and that their responses would be anonymous and fully confidential. Each participating physician filled out a written informed consent form before receiving the study questionnaire.

This study was carried out according to the ethical principles of the Declaration of Helsinki, and all necessary official and ethical approvals were obtained before data collection. The official Institutional Review Board (IRB) approval was obtained from the Directorate of Health Affairs in Aseer, KSA (REC\# 1-9-2019).

During data collection, the investigators were available to answer any questions that participants had about the questionnaire. The investigators then collected all filled questionnaires on the same day of the visit.

Statistical analysis. Collected data was analyzed using the Statistical Package for Social Sciences, version 25 (IBM Corp, Armonk, NY, USA). Descriptive statistics were calculated in the form of frequencies and percentages. The Chi-square $\left(\chi^{2}\right)$ test was applied to compare between stereotyping and non-stereotyping PHC physicians according to their personal characteristics. Multivariate binary logistic regression (with backward selection method) was applied to identify determinants of stereotyping among PHC physicians. A $p$-value less than 0.05 was considered significant.

Results. Table 1 shows that age of $44.4 \%$ of PHC physicians in Aseer Region ranged from 30-40 years, $52.8 \%$ were males, $68 \%$ were Saudi, $67.6 \%$ were married, $80.8 \%$ were currently non-smokers, and $63.2 \%$ had bachelor's degrees. The specialty of $48.4 \%$ was general practice, while $60.8 \%$ were general practitioners. Most participant physicians had less than 5 years' experience in PHC (40.8\%), or 5-10 years' experience in PHC (42.8\%). The monthly income of $61.6 \%$ was more than 20,000 Saudi Riyals.

Table 2 shows that the patient sociodemographic characteristics most likely to trigger implicit stereotyping among PHC physicians were gender, educational level, and status as a physician. On the other hand, the characteristics of patient appearance that were mostly likely to trigger implicit stereotyping among PHC physicians were clothing and overall hygiene.

Figure 1 shows that 159 PHC physicians (63.6\%) showed implicit stereotyping in response to patients' personal characteristics, while 144 (57.6\%) showed stereotyping in response to appearance.

Table 3 shows that implicit stereotyping with respect to patient characteristics was significantly higher among younger PHC physicians $(p=0.009)$, females $(p=0.018)$, those with bachelor's degrees $(p<0.001)$, those with general practice as their specialty and those with general practitioner position ( $p<0.001$ for both), as well as their years of experience in PHC, with highest prevalence of stereotyping among those with less than 5 years' experience in PHC $(p=0.009)$. However, implicit stereotyping with respect to patient characteristics did not differ significantly according to the PHC physicians' nationality, marital status, smoking status, or their monthly income.

Table 4 shows that implicit stereotyping with respect to patient appearance was highest among PHC physicians whose specialty was general practice $(p=0.033)$. However, implicit stereotyping with respect 
to appearance did not differ significantly by other PHC physicians' personal characteristics.

Table 5 shows that the binary logistic regression model for implicit stereotyping (using backward selection) with respect to patient characteristics revealed a significant association between PHC physicians' qualifications with higher stereotyping among less-qualified physicians $(\operatorname{Exp}(B)=0.212$, $<0.001)$ and position with higher stereotyping among senior physicians $(\operatorname{Exp}(B)=0.576, p=0.011)$. On the other hand, regarding patient appearance, there were significant associations between physicians' specialty with higher stereotyping among PHC physicians of dentistry and other specialties $(\operatorname{Exp}(B)=0.697, p<0.001)$ and position with higher stereotyping among general practitioners $(\operatorname{Exp}(B)=1.580, p=0.007)$.

Discussion. The present study showed that participating healthcare physicians were almost evenly split in terms of gender, with most physicians being Saudi nationals. About one third had postgraduate degrees, with their specialty mainly being general practice and family medicine, while approximately one fifth were dentists, and the majority of participant physicians had less than 10 years' experience in PHC.

This variability in healthcare physicians' personal characteristics can provide a wide range of choices to satisfy patients attending PHC centers. Mandil et $\mathrm{al},{ }^{15}$ noted that most female patients in KSA with obstetric, gynecologic, or other medical complaints preferred to be examined by healthcare physicians of the same gender, with avoidance of embarrassment the main reason for their choice. However, the physicians' characteristic that was most in demand among patients was greater experience as measured by years in medical practice. Walston et $\mathrm{al}^{16}{ }^{16}$ noted that the healthcare workforce in KSA has the honor of being described as the United Nations of Health Professionals, with several countries being represented in the healthcare system since approximately one-fourth of the population is composed of foreign nationals.

Results of the present study revealed that more than half of physicians were more comfortable dealing with patients of specific personal characteristics or appearance. The main patient characteristics that may trigger implicit stereotyping among PHC physicians were patients' gender, educational level, and status as a physician. Regarding patient appearance, physicians were most sensitive to patients' clothing and overall hygiene.

These findings support the hypothesis of this study, which was that most PHC physicians in Aseer Region, Saudi Arabia, implicitly stereotype based on their patients' characteristics or appearance. These results are also in accordance with that noted by Moskowitz et al, ${ }^{14}$ who stated that physicians are aware of groups social stereotypes and, therefore, are commonly vulnerable to have stereotypes, which are usually implicitly triggered, and may affect their diagnoses, treatment recommendations, expectations regarding whether their patients will comply to suggested treatment, and both verbal and non-verbal behaviors regarding patients during interactions.

There is considerable evidence that patients' characteristics may have an impact on both physicians' behavior during medical encounters and on the diagnoses and treatments their patients received..$^{13}$ Patients' educational level and status as a physician were reported to be active triggers for stereotyping among the treating physicians. It was repeatedly stated that in the hospital, doctors make the worst patients. ${ }^{17,18}$ Najman et al, ${ }^{19}$ stressed that physicians experience a wide range of negative stereotypes during contacts with their patients, mainly toward unhygienic patients, alcohol or
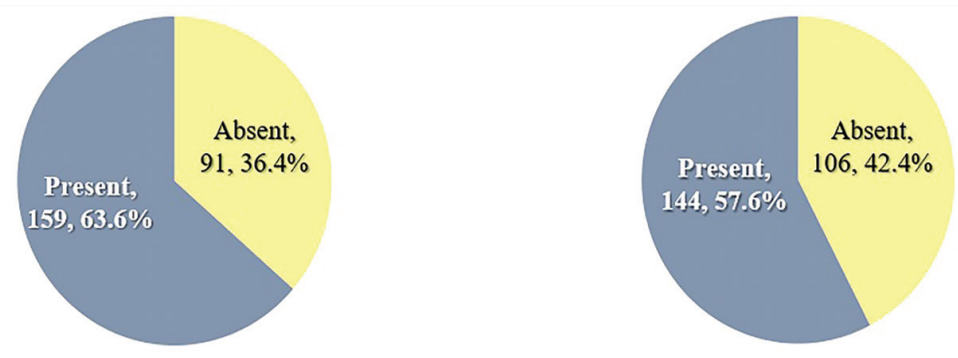

\section{Implicit stereotyping toward patient's} personal characteristics

\section{Implicit stereotyping toward pattient's appearance}

Figure 1 - Prevalence of PHC physicians' implicit stereotyping toward patients' personal characteristics and appearance. 
Table 1 - Personal characteristics of primary health care physicians in Aseer Region.

\begin{tabular}{lc}
\hline Personal characteristics & $\mathrm{n}(\%)$ \\
\hline Age groups & \\
$<30$ years & $63(25.2)$ \\
$30-40$ years & $111(44.4)$ \\
>40 years & $76(30.4)$ \\
Gender & \\
Male & $132(52.8)$ \\
Female & $118(47.2)$ \\
Nationality & \\
Saudi & $170(68.0)$ \\
Non-Saudi & $80(32.0)$ \\
Marital status & \\
Single & $75(30.0)$ \\
Married & $169(67.6)$ \\
Widow/divorced & $6(2.4)$ \\
Smoking status & \\
Currently non-smoker & $202(80.8)$ \\
Currently smoker & $48(19.2)$ \\
Qualifications & \\
Bachelor & $158(63.2)$ \\
Master/diploma & $56(22.4)$ \\
MD/fellowship & $36(14.4)$ \\
Specialty & \\
General practice & $121(48.4)$ \\
Family medicine & $55(22.0)$ \\
Dentistry & $54(21.6)$ \\
Others* & $20(8.0)$ \\
Position & \\
General practitioner & $152(60.8)$ \\
Registrar & $61(24.4)$ \\
Senior registrar & $21(8.4)$ \\
Consultant & $16(6.4)$ \\
Years of experience in PHC & \\
<5 years & $102(40.8)$ \\
5-10 years & $107(42.8)$ \\
>10 years & $41(16.4)$ \\
Physicians' monthly income & \\
$<10,000$ SR & $26(10.4)$ \\
10,000-20,000 SR & $70(28.0)$ \\
$>20,000$ SR & $154(61.6)$ \\
\hline PHC: primary care physician, SR: Suadi Riyals, primary care physicians other \\
$\quad$ than general practitioners, family physicians, or dentists \\
\hline \\
\hline
\end{tabular}

drug abusers, obese patients, and patients with mental disorders.

Several studies have explained physicians' implicit stereotyping toward their patients. Moskowitz et $\mathrm{al},{ }^{14}$ stated that, in medical training, it is essential to note that certain diseases can be associated with particular patients and that specific categories of patients are more prone to demonstrate certain diseases. Subsequently, most clinicians become comfortable in classifying individuals according to social groups. This sort of bias is mainly an unconscious process that leads to implicitly influenced decision-making and discriminatory behavior. ${ }^{7}$ Further explanation has been suggested by Banaji et $\mathrm{al},{ }^{20}$ who discussed 2 levels of cognition. The first is explicit or higher-level thinking, which refers to attitudes and beliefs that we have and report as rational. The second is implicit or lower-level thinking, which refers to attitudes that are not readily apparent to the individual, being more automatic and unconscious. ${ }^{20}$

Findings of the present study revealed that implicit stereotyping toward patient characteristics was significantly higher among PHC physicians who were younger, female, having bachelor's degrees, having general practice as their specialty, or having a position as general practitioner, as well as those with less experience in PHC. However, after controlling for possible confounders, binary logistic regression analysis revealed that PHC physicians qualification and position were significantly associated with stereotyping based on patient characteristics.

On the other hand, PHC physicians' implicit stereotyping based on patient appearance was significantly higher only among general practitioners.

Table 2 - Primary healthcare physicians' attitudes toward characteristics of patients that may trigger implicit stereotyping.

\begin{tabular}{|c|c|c|c|c|c|}
\hline Patients' characters & $\begin{array}{l}\text { Strongly } \\
\text { disagree }\end{array}$ & Disagree & Neutral & Agree & Strongly agree \\
\hline \multicolumn{6}{|l|}{ Sociodemographic characteristics } \\
\hline Patient's gender makes difference in management & $7(2.8)$ & $12(4.8)$ & $31(12.4)$ & $116(46.4)$ & $84(33.6)$ \\
\hline Highly educated patients are difficult & $0(0.0)$ & $11(4.4)$ & $36(14.4)$ & $148(59.2)$ & $55(22.0)$ \\
\hline Physicians are more difficult & $0(0.0)$ & $17 \quad(6.8)$ & $30(12.0)$ & $180(72.0)$ & $23(9.2)$ \\
\hline Low educated patients are difficult & $0(0.0)$ & $20(8.0)$ & $41(16.4)$ & $180(72.0)$ & $9(3.6)$ \\
\hline Nationality of patient affects consultation & $8(3.2)$ & $99(39.6)$ & $65(26.0)$ & $72(28.8)$ & $6(2.4)$ \\
\hline Smokers are less adherent to medication & $6(2.4)$ & $121(48.4)$ & $71(28.4)$ & $52(20.8)$ & $0 \quad(0.0)$ \\
\hline Certain patients are less likely to adhere to their appointments & $2(0.8)$ & $34(13.6)$ & $33(13.2)$ & $167(66.8)$ & $14 \quad(5.6)$ \\
\hline Tribe of the patient is suggestive of patient's attitude toward his/her disease & $6(2.4)$ & $72(28.8)$ & $68(27.2)$ & $102(40.8)$ & $2(0.8)$ \\
\hline Low socioeconomic class patients do not comply to treatment plan & $2(0.8)$ & $208(83.2)$ & 4 (1.6) & $28(11.2)$ & $8(3.2)$ \\
\hline \multicolumn{6}{|l|}{ Patient's appearance } \\
\hline Patient's clothing appearance affects my communication with him/her & $4(1.6)$ & $17 \quad(6.8)$ & $26(10.4)$ & $107(42.8)$ & $96(38.4)$ \\
\hline Patient's name is a factor influencing his/her compliance & $7(2.8)$ & $145(58.0)$ & $29(11.6)$ & $52(20.8)$ & $17 \quad(6.8)$ \\
\hline Patient's overall hygiene appearance affects my communication with him/her & $2(0.8)$ & 9 (3.6) & $41(16.4)$ & $165(66.0)$ & $33(13.2)$ \\
\hline Patient's accent is suggestive of poor compliance & $1(0.4)$ & $28(11.2)$ & $89(35.6)$ & $128(51.2)$ & 4 (1.6) \\
\hline I feel discomfort dealing with overweight/obese patients & $6(2.4)$ & $66(26.4)$ & $135(54.0)$ & $40(16.0)$ & $3(1.2)$ \\
\hline Skin color indicates patient's compliance with instructions & $25(10.0)$ & $197(78.8)$ & $10 \quad(4.0)$ & $18(7.2)$ & $0 \quad(0.0)$ \\
\hline
\end{tabular}


Table 3 - Prevalence of implicit stereotyping with respect to patient characteristics according to primary healthcare (PHC) physicians' personal characteristics.

\begin{tabular}{|c|c|c|c|}
\hline \multirow[t]{2}{*}{ Characteristics } & Absent $(\mathrm{n}=91)$ & Present $(n=159)$ & \multirow[t]{2}{*}{$P$-value } \\
\hline & \multicolumn{2}{|c|}{$\mathrm{n}(\%)$} & \\
\hline \multicolumn{4}{|l|}{ Age groups } \\
\hline$<30$ years & $13(20.6)$ & $50(79.4)$ & \multirow{3}{*}{0.009} \\
\hline $30-40$ years & $48(43.2)$ & $63(56.8)$ & \\
\hline$>40$ years & $30(39.5)$ & $46(60.5)$ & \\
\hline \multicolumn{4}{|l|}{ Gender } \\
\hline Male & $57(43.2)$ & $75(56.8)$ & \multirow{2}{*}{0.018} \\
\hline Female & $34(28.8)$ & $84(71.2)$ & \\
\hline \multicolumn{4}{|l|}{ Nationality } \\
\hline Saudi & $64(37.6)$ & $106(62.4)$ & \multirow{2}{*}{0.550} \\
\hline Non-Saudi & $27(33.8)$ & $53(66.3)$ & \\
\hline \multicolumn{4}{|l|}{ Marital status } \\
\hline Single & $21(28.0)$ & $54(72.0)$ & \multirow{3}{*}{0.184} \\
\hline Married & $68(40.2)$ & $101(59.8)$ & \\
\hline Widow/Divorced & $2(33.4)$ & $4(66.7)$ & \\
\hline \multicolumn{4}{|l|}{ Smoking status } \\
\hline Currently non-smoker & $74(36.6)$ & $128(63.4)$ & \multirow{2}{*}{0.875} \\
\hline Currently smoker & $17(35.4)$ & $31(64.6)$ & \\
\hline \multicolumn{4}{|l|}{ Qualifications } \\
\hline Bachelor & $32(20.3)$ & $126(79.7)$ & \multirow{3}{*}{$<0.001$} \\
\hline Master/Diploma & $25(44.6)$ & $31(55.4)$ & \\
\hline MD/Fellowship & $34(94.4)$ & $2(5.6)$ & \\
\hline \multicolumn{4}{|l|}{ Specialty } \\
\hline General Practice & $27(22.3)$ & $94(77.7)$ & \multirow{4}{*}{$<0.001$} \\
\hline Family Medicine & $39(70.9)$ & $16(29.1)$ & \\
\hline Dentistry & $18(33.3)$ & $36(66.7)$ & \\
\hline Others * & $7(35.0)$ & $13(65.0)$ & \\
\hline \multicolumn{4}{|l|}{ Position } \\
\hline General Practitioner & $35(23.0)$ & $117(77.0)$ & \multirow{4}{*}{$<0.001$} \\
\hline Registrar & $28(45.9)$ & $33(54.1)$ & \\
\hline Senior Registrar & $16(76.2)$ & $5(23.8)$ & \\
\hline Consultant & $12(75.0)$ & $4(25.0)$ & \\
\hline \multicolumn{4}{|l|}{ Years of experience in PHC } \\
\hline$<5$ years & $26(25.5)$ & $76(74.5)$ & \multirow{3}{*}{0.009} \\
\hline $5-10$ years & $45(42.1)$ & $62(57.9)$ & \\
\hline$>10$ years & $20(48.8)$ & $21(51.2)$ & \\
\hline \multicolumn{4}{|l|}{ Physicians' monthly income } \\
\hline$<10,000$ SR & $9(34.6)$ & $17(65.4)$ & \multirow{3}{*}{0.375} \\
\hline $10,000-20,000$ SR & $21(30.0)$ & $49(70.0)$ & \\
\hline$>20,000 \mathrm{SR}$ & $61(39.6)$ & $93(60.4)$ & \\
\hline
\end{tabular}

However, after controlling for confounders, binary logistic regression analysis revealed that both PHC physicians' specialty and position were significantly associated with stereotyping based on patient appearance.

Several researchers have discussed the impact of physicians' gender on their judgment. Hall et $\mathrm{al},{ }^{21}$ considered it as a significant factor in clinical relationships, as female physicians were found to like their patients more than their male colleagues do. At the same time, patients felt that female physicians liked them better. Moreover, patients preferred female
Table 4 - Prevalence of implicit stereotyping with respect to patient appearance according to primary healthcare (PHC) physicians' personal characteristics.

\begin{tabular}{|c|c|c|c|}
\hline Characteristics & $\begin{array}{r}\text { Absent }(\mathrm{n}=106) \\
\mathrm{n}(\%\end{array}$ & $\begin{array}{l}\text { Present } \\
(n=144)\end{array}$ & $P$-value \\
\hline \multicolumn{4}{|l|}{ Age groups } \\
\hline$<30$ years & $22(34.9)$ & $41(65.1)$ & \multirow{3}{*}{0.381} \\
\hline $30-40$ years & $50(45.0)$ & $61(55.0)$ & \\
\hline$>40$ years & $34(44.7)$ & $42(55.3)$ & \\
\hline \multicolumn{4}{|l|}{ Gender } \\
\hline Male & $52(39.4)$ & $80(60.6)$ & \multirow{2}{*}{0.309} \\
\hline Female & $54(45.8)$ & $64(54.2)$ & \\
\hline \multicolumn{4}{|l|}{ Nationality } \\
\hline Saudi & $65(38.2)$ & $105(61.8)$ & \multirow{2}{*}{0.052} \\
\hline Non-Saudi & $41(51.2)$ & $39(48.8)$ & \\
\hline \multicolumn{4}{|l|}{ Marital status } \\
\hline Single & $27(36.0)$ & $48(64.0)$ & \multirow{3}{*}{0.341} \\
\hline Married & 77 (45.6) & $92(54.4)$ & \\
\hline Widow/Divorced & $2(33.3)$ & $4(66.7)$ & \\
\hline \multicolumn{4}{|l|}{ Smoking status } \\
\hline Currently non-smoker & $87(43.1)$ & $115(56.9)$ & \multirow{2}{*}{0.660} \\
\hline Currently smoker & $19(39.6)$ & $29(60.4)$ & \\
\hline \multicolumn{4}{|l|}{ Qualifications } \\
\hline Bachelor & $62(39.2)$ & $96(60.8)$ & \multirow{3}{*}{0.362} \\
\hline Master/Diploma & $28(50.0)$ & $28(50.0)$ & \\
\hline MD/Fellowship & $16(44.4)$ & $20(55.6)$ & \\
\hline \multicolumn{4}{|l|}{ Specialty } \\
\hline General Practice & $41(33.9)$ & $80(66.1)$ & \multirow{4}{*}{0.033} \\
\hline Family Medicine & $24(43.6)$ & $31(56.4)$ & \\
\hline Dentistry & $30(55.6)$ & $24(44.4)$ & \\
\hline Others * & $11(55.0)$ & $9(45.0)$ & \\
\hline \multicolumn{4}{|l|}{ Position } \\
\hline General Practitioner & $66(43.4)$ & $86(56.6)$ & \multirow{4}{*}{0.208} \\
\hline Registrar & $29(47.5)$ & $32(52.5)$ & \\
\hline Senior Registrar & $8(38.1)$ & 13 (61.9) & \\
\hline Consultant & $3(18.8)$ & $13(81.3)$ & \\
\hline \multicolumn{4}{|l|}{ Years of experience in $P H C$} \\
\hline$<5$ years & $42(41.2)$ & $60(58.8)$ & \multirow{3}{*}{0.363} \\
\hline $5-10$ years & $50(46.7)$ & $57(53.3)$ & \\
\hline$>10$ years & $14(34.1)$ & 27 (65.9) & \\
\hline \multicolumn{4}{|l|}{ Physicians' monthly income } \\
\hline$<10,000 \mathrm{SR}$ & $10(38.5)$ & $16(61.5)$ & \multirow{3}{*}{0.874} \\
\hline $10,000-20,000 \mathrm{SR}$ & $29(41.4)$ & $41(58.6)$ & \\
\hline$>20,000 \mathrm{SR}$ & $67(43.5)$ & $87(56.5)$ & \\
\hline $\begin{array}{r}* \text { Primary care phys } \\
\text { physici }\end{array}$ & $\begin{array}{l}\text { other than gen } \\
\text { r dentists, SR: }\end{array}$ & $\begin{array}{l}\text { ractitioners, } \\
\text { Riyals }\end{array}$ & \\
\hline
\end{tabular}

physicians over male physicians. However, Crandall et $\mathrm{al}^{, 22}$ and Weitzman et $\mathrm{al}^{23}$ did not have the same findings. Hojat et al, ${ }^{24}$ noted that, regarding empathy, women scored better than men, but there is no evidence that this difference has an impact in medical practice. Nevertheless, studies, including ours, continue to provide clues for significant gender differences in emotionally charged moral appraisals. ${ }^{25}$

Therefore, it is suggested that training of PHC physicians in cultural competency can play a significant role in reducing the implicit discrimination that 
Table 5 - Binary logistic regression model for implicit stereotyping among PHC physicians with respect to patient characteristics and appearance.

\begin{tabular}{|c|c|c|c|c|c|c|c|}
\hline \multirow[t]{2}{*}{ Variables } & \multirow[t]{2}{*}{ B } & \multirow[t]{2}{*}{ S.E. } & \multirow[t]{2}{*}{ Wald } & \multirow[t]{2}{*}{$\operatorname{Exp}(B)$} & \multirow[t]{2}{*}{$P$-value } & \multicolumn{2}{|c|}{$95 \% \mathrm{CI}$} \\
\hline & & & & & & Lower & Upper \\
\hline \multicolumn{8}{|l|}{ Characteristics } \\
\hline Qualification & -1.552 & 0.263 & 34.937 & 0.212 & $<0.001$ & 0.127 & 0.354 \\
\hline Position & -0.552 & 0.217 & 6.457 & 0.576 & 0.011 & 0.376 & 0.881 \\
\hline Constant & 2.626 & 0.607 & 18.734 & 13.818 & $<0.001$ & -- & -- \\
\hline \multicolumn{8}{|l|}{ Appearance } \\
\hline Specialty & -0.361 & 0.099 & 13.444 & 0.697 & $<0.001$ & 0.574 & 0.845 \\
\hline Position & 0.458 & 0.171 & 7.168 & 1.580 & 0.007 & 1.130 & 2.210 \\
\hline Constant & 0.456 & 0.308 & 2.198 & 1.578 & 0.138 & -- & -- \\
\hline
\end{tabular}

prevents certain groups of patients from getting the necessary care they demand. ${ }^{26,27}$

Study limitations. The self-reporting nature of the study tool in the present study may have led to over- or underestimation of participants' degree of bias. Moreover, the cross-sectional nature of our study does not permit considering the causality of the relationship between compared variables. In addition, this study population included physicians at the PHC level only, and results may not generalize to secondary or tertiary care physicians or physicians at private hospitals. However, a point of strength for the current study is the lack of previous studies in KSA that explored stereotyping and its impact among PHC physicians. Moreover, findings of the present study can help regarding future research related to linking the mental processes detailed in the multi-stage model of stereotyping to health discrepancies.

In conclusion, most $\mathrm{PHC}$ physicians in Aseer Region, $\mathrm{KSA}$, are liable to implicit stereotyping. The most common sociodemographic characteristics that trigger implicit stereotyping are patients' gender, educational level, and status as a physician. On the other hand, among characteristics of patient appearance that may trigger implicit stereotyping among PHC physicians, the most common characteristics were the appearance of their clothing and overall hygiene. Stereotyping among PHC physicians was higher among those who were young, female, and those who had bachelor's degrees, or had general practice as their specialty, or who were general practitioners.

Therefore, it is advisable to train PHC physicians on cultural competency to reduce unintentional acts of discrimination toward their patients. Moreover, results suggest the importance of teaching undergraduate medical students about stereotype threat and how to avoid it in order to prepare them for their medical careers. In addition, further studies are needed to explore stereotyping in different regions of KSA, among secondary and tertiary care physicians, and at private hospitals.

Acknowledgment. The authors gratefully acknowledge Editage (www.editage.com) for the provided professional English Language editing.

\section{References}

1. Abdou CM, Fingerhut AW, Jackson JS, Wheaton F. Healthcare stereotype threat in older adults in the health and retirement study. Am J Prev Med 2016; 50: 191-198.

2. Gordon HS, Street RL Jr, Sharf BF, Souchek J. Racial differences in doctors' information-giving and patients' participation. Cancer 2006; 107: 1313-1320.

3. van Ryn M, Burgess D, Malat J, Griffin J. Physicians' perceptions of patients' social and behavioral characteristics and race disparities in treatment recommendations for men with coronary artery disease. Am J Public Health 2006; 96: 351-357.

4. Zestcott CA, Blair IV, Stone J. Examining the presence, consequences, and reduction of implicit bias in health care: A narrative review. Group Process Intergroup Relat 2016; 19 : 528-542.

5. Nelson T. The Handbook of Prejudice, Stereotyping, and Discrimination. London (UK): Psychology Press; 2009.

6. Kunda Z, Spencer SJ. When do stereotypes come to mind and when do they color judgment? A goal-based theoretical framework for stereotype activation and application. Psychol Bull 2003; 129: 522-544.

7. Dehon E, Weiss N, Jones J, Faulconer W, Hinton E, Sterling S. A systematic review of the impact of physician implicit racial bias on clinical decision making. Acad Emerg Med 2017; 24: 895-904.

8. Moskowitz GB. On the control over stereotype activation and stereotype inhibition. Soc Personal Psychol Compass 2010; 4: 140-158.

9. Marcelin JR, Siraj DS, Victor R, Kotadia S, Maldonado YA. The impact of unconscious bias in healthcare: How to recognize and mitigate it. J Infect Dis 2019; 220: S62-S73. 
10. D’Anna LH, Hansen M, Mull B, Canjura C, Lee E, Sumstine S. Social discrimination and health care: A multidimensional framework of experiences among a low-income multiethnic sample. Soc Work Public Health 2018; 33: 187-201.

11. Giddon DB. Should dentists become 'oral physicians'? Yes, dentists should become 'oral physicians'. J Am Dent Assoc 2004; 135.

12. Raosoft. sample size calculator [Internet]. [Updated 2004. Accessed 2020 January 15]. Available from: http://www.raosoft. com/samplesize.html

13. van Ryn M, Burke J. The effect of patient race and socioeconomic status on physicians' perceptions of patients. Soc Sci Med 2000; 50: 813-828.

14. Moskowitz GB, Stone J, Childs A. Implicit stereotyping and medical decisions: unconscious stereotype activation in practitioners' thoughts about African Americans. Am J Public Health 2012; 102: 996-1001.

15. Mandil AM, Alhayyan RM, Alshalawi AA, Alemran AS, Alayed MM. Preference of physicians' gender among male and female primary health care clinic attendees in a university hospital in Saudi Arabia. Saudi Med J 2015; 36: 1011.

16. Walston S, Al-Harbi Y, Al-Omar B. The changing face of healthcare in Saudi Arabia. Ann Saudi Med 2008; 28: 243-250.

17. Kay M, Mitchell G, Clavarino A, Doust J. Doctors as patients: a systematic review of doctors' health access and the barriers they experience. Br J Gen Pract 2008; 58: 501-508.

18. Carter J, Smith EF, Gelves-Gomez F. Doctoring knowledge or acknowledging doctors? Geographical Research 2018; 56: 484-488.
19. Puddifoot K. Stereotyping Patients. J Soc Philos 2019; 50: 69-90.

20. Banaji MR, Greenwald AG. Blindspot: Hidden biases of good people. New York (NY): Random House Publishing; 2014. p. 82-85.

21. Hall JA, Horgan TG, Stein TS, Roter DL. Liking in the physician--patient relationship. Patient Educ Couns 2002; 48 : 69-77.

22. Crandall SJ, Davis SW, Broeseker AE, Hildebrandt C. A longitudinal comparison of pharmacy and medical students' attitudes toward the medically underserved. Am J Pharm Educ 2008; $72: 148$.

23. Weitzman CC, Freudigman K, Schonfeld DJ, Leventhal JM. Care to underserved children: Residents' attitudes and experiences. Pediatrics 2000; 106: 1022-1027.

24. Hojat M. Empathy in Patient Care: Antecedents, Development, Measurement, and Outcomes New York (NY): Springer; 2007.

25. Fumagalli M, Ferrucci R, Mameli F, Marceglia S, Mrakic-Sposta S, Zago S, et al. Gender-related differences in moral judgments. Cogn Process 2010; 11: 219-226.

26. Groman R, Ginsburg J. Racial and ethnic disparities in health care: a position paper of the American college of physicians. Ann Intern Med 2004; 141: 226-232.

27. Castro A, Ruiz E. The effects of nurse practitioner cultural competence on Latina patient satisfaction. J Am Acad Nurse Pract 2009; 21: 278-286. 